\title{
Informed Trading of Futures Markets During the Financial Crisis: Evidence from the VPIN
}

\author{
Yen-Hsien Lee ${ }^{1}$, Wen-Chien Liu ${ }^{1} \&$ Chia-Lin Hsieh ${ }^{1}$ \\ ${ }^{1}$ Department of Finance, Chung Yuan Christian University, Taiwan, R.O.C. \\ Correspondence: Wen-Chien Liu, Department of Finance, Chung Yuan Christian University, 200, Chung Pei Rd., \\ Chung Li, Taiwan 32023, R.O.C. Tel: 886-3-265-5706. E-mail: wcliu@cycu.edu.tw
}

Received: July 4, 2017

Accepted: July 29, 2017

Online Published: August 10, 2017

doi:10.5539/ijef.v9n9p123

URL: https://doi.org/10.5539/ijef.v9n9p123

\begin{abstract}
This paper examines the impact of informed trading on futures returns during the 2008-2009 financial crisis. To precisely capture the informed trading in the highly volatile market during this period, we adopt the Volume-Synchronized Probability of Informed Trading (VPIN) of Easley, Hvidkjaer and O'Hara (2012) as our main measurement for informed trading. Besides, we also use a unique transaction dataset with investor identity to classify investors into domestic and foreign institutional investors, which the foreign institutional investors are supposed to be characterized by a higher degree of informed trading. Our empirical results show that the VPIN of foreign institutional investors has indeed significantly positive impacts on futures returns at the individual level. By contrast, the effect of the VPIN of domestic institutional investors on futures returns is only significant on Wednesdays, which could be seen as a special kind of day-of-the-week effect.
\end{abstract}

Keywords: VPIN, day-of-the-week effect, GARCH, futures market, financial crisis

\section{Introduction}

In this study, we mainly investigate the influences of informed trading on the futures returns during the period of the 2008-2009 financial crisis. During this unstable period, there were supposed to be more informed traders in the market than in normal periods. Hence, we have two channels through which to capture such informed trading. First, we adopt the Volume-Synchronized Probability of Informed Trading (VPIN) of Easley, Hvidkjaer and O'Hara (2012) to measure such informed trading behavior. In addition, secondly, we also use the unique futures tick-by-tick transaction data compiled by the Taiwan Futures Exchange (TAIFEX) that can help identify various kinds of institutional investors into foreign institutional investors with superior information and domestic institutional investors with inferior information. In addition, we also take the day-of-the-week effect into consideration to observe the additional interactive influences of informed trading and the day-of-the-week effect on the futures returns.

Our main goal is to understand the trading behavior of informed trading in a volatile market. Therefore, we examine this issue from four points of view. First, we seek to determine if the informed trading measured by the VPIN has a significant effect on futures returns overall. Secondly, we examine the day-of-the-week effect in the Taiwan futures market. Thirdly, we go further to examine the various degrees of impacts of the VPIN for different types of institutional investors (i.e., domestic versus foreign institutional investors) on futures returns. Finally, we also investigate the interaction effect between the VPIN and day-of-the-week effect on the returns of the futures market. Empirically, we find that the VPIN of foreign institutional investors has a significant positive effect on futures returns. In comparison, the VPIN of domestic institutional investors had a positive effect on futures returns that are only conditional on the day-of-the-week effect for Wednesday.

Overall, we contribute to the literature in three ways. First, this study may lead to a better understanding of the effect of informed trading on futures markets, especially when using a good measure of the volatile market of the VPIN. Secondly, as we use the unique tick-by-tick transactions data that can distinguish the types of investors into domestic and foreign institutional investors, it would be helpful to more fully understand the role of different investors in a market. Third, compared to the traditional weekend and day-of-the-week effects, this study also has broad implications in the area of the day-of-the-week effect.

The remainder of this paper proceeds as follows. Section 2 discusses the previous literature and the development 
of our hypotheses. Section 3 describes the data used and methodology in the study. In Section 4, the empirical results are discussed, and Section 5 presents the conclusions.

\section{Theoretical Background and Hypothesis Development}

\subsection{The Influence of the Day-of-the-Week Effect on Financial Markets}

The day-of-the-week effect of return patterns on financial markets is one of characteristic phenomenon in the past studies. In other words, the returns on equity assets appear to be lower or higher on certain days compared to other days of the week. The day-of-the-week effect was first observed by Fields (1931) who pointed out that the U.S. stock market consistently experienced significant negative returns on Mondays and significant positive returns on Friday. There are also some earlier empirical studies such as Cross (1973), French (1980) and Harris (1986) that indicated that Monday had lower returns in the stock markets; that is, the returns were interrelated with the day-of-the-week effect.

After executing the policy of two days off per week, some empirical studies point out the influence of the day-of-the-week effect in the financial markets for Taiwan (Note 1). By using data for Taiwan stocks, Zhan and Wang (2007) found that returns on Mondays are significantly negative. Moreover, returns on Mondays are not evenly distributed within a month; instead, they are concentrated in the third and the fourth weeks of the month. Lean et al. (2007) carried on the multinational study using daily stocks and concluded that the lowest mean return was on Monday and the highest mean return on Friday (Note 2). Yan et al. (2016) adopted a unique dataset for the Taiwan Stock Exchange to show that firms with high short selling activity have higher returns on Mondays; short covering activity is relatively high, while Friday returns are more negative. Based on the above, we propose our first hypothesis as:

Hypothesis 1: The day-of-the-week effect affects the futures returns, especially on Mondays, Wednesdays and Fridays.

\subsection{The Influence of the VPIN on Financial Markets}

Regarding the estimation model of the informed trading, the most commonly used model in the literature is the traditional probability of informed trading model (PIN) proposed by Easley et al. (1996). However, there are two shortcomings in this model. First, it omitted the problem of trading non-synchronization, which may be unable to capture the real effect in complex financial market, especially the high-frequency trading environment today. Second, in order to fully add all kinds of effects to the original PIN model, the amount of parameters that need to be estimated is also increased, which resulted in the difficulty of estimation. Hence, Easley et al. (2012) proposed a newly updated model named Volume-Synchronized Probability of Informed Trading (VPIN), which mainly overcome these two problems. The distinguishing features of this new model are shown as follows. At first, they adjust the bias from the trading volume imbalance and non-synchronization in their original model PIN, as well as more precisely capture the effects from short-term volatility. Besides, originally, for the estimation of the traditional probability of informed trading model, they adopt the method of parametric model estimation, such as maximum likelihood estimation. In the new model VPIN of Easley et al. (2012), they changed to use non-parametric estimation method for the probability of informed trading (here is VPIN), which is the expectation of the imbalance in the trading volume. At the same time, this new change also facilitates the calculation process, and enables the results to be observed more directly, and thereby become more convincing.

Easley et al. (2012) strengthened the practicality of the probability of informed trading in a paper that was written in 2010, and became the important guidelines for the following studies. They also provided evidence to show that the VPIN was a good indicator in a high-frequency trading environment characterized by short-term volatility. In addition, its calculation was based on the tick rule (TR), and was thus also referred to as TR-VPIN. Easley et al. (2011a) used the VPIN to observe the flash crash event in the U.S. stock market that took place on May 6, 2010. They found that, with the cumulative distribution of the VPIN reaching its highest point on the eve of the crash, its effect became more obvious than the cumulative distribution of the VIX. Furthermore, Easley et al. (2011b) illustrated the applicability of the VPIN, and based on its calculation method also introduced the idea of a futures contract involving the VPIN metrics as the underlying FVPIN. A FVPIN index was also proposed to help the securities market to reduce the bid-ask spread and price discovery mechanism. Besides, Chakrabarty, Pascual and Shkilko (2015) also pointed out that the tick rule was more accurate in the market, which illustrated that it was better to use the tick rule in the model of VPIN.

However, regarding the literature of the VPIN in futures markets is still not as well developed as for other markets. Che et al. (2014) contended that there was a large quantity of information contained in futures contracts and that the larger the proportion of informed traders, the higher the volatility of the price. Therefore, this paper 
aims to examine the impact of the VPIN on the futures market. Based on previous studies, we state our next hypothesis as follows:

Hypothesis 2-1: Traders who have informed trading will impact on futures returns.

Due to the above-mentioned research for the influence of the VPIN on the returns in the financial market as well as the impact of the day-of-the-week effect on the market returns, we combine these two effects to further explore the influence of these two factors in formulating our next hypothesis:

Hypothesis 2-2: Informed traders have a positive effect on returns due to the day-of-the-week effect.

\subsection{The Impact of Different Types of Investors on Financial Markets}

By using daily returns on the NYSE portfolio and individual securities, Sias and Starks (1997) indicated that trading from institutional investors contributes to serial correlation in daily returns. They also pointed out that information reflected by institutional investors has the same speed of price adjustment. Some studies claim that the returns on stock markets are correlated with domestic or foreign institutional investors. Bailey et al. (2009) reported that orders from institutional investors placed on the Shanghai Stock Exchange strongly influence stock prices and institutional investors favor stocks with large capitalizations. Similar evidence also exists in the Taiwan stock market. For example, Lin and Chen (2006) examined the correlation between foreign institutional investors and the Taiwan stock market, their results show that foreign institutional investors significantly impact the returns of the Taiwan stock market and also implied that their behavior resulted in better returns. Lien at el. (2013) indicated that the involvement of foreign institutional investors in the Taiwan stock market has grown significantly. Besides, foreign institutional investors could continue to play a considerable role in the market's development in the future.

In addition to the results from stock markets, there were also studies from the futures market. Take Xu and Wan (2015) for example, they proposed that the CSI 300 futures trading from institutional investors had more significant price discovery effects on Chinese A-share market than individual investors, which implied trader types indeed played an important role. Meanwhile, some studies have also investigated the relationships between different traders and the returns on futures in the Taiwan futures market. Lai and Wang (2014) used trading data on Taiwan stock index futures contracts obtained directly from the TAIFEX. They pointed out that foreign investors have the ability to forecast futures returns.

Overall, we may expect that different types of investors have different impacts on the returns in financial markets, which leads to our third hypothesis:

Hypothesis 3: The behavior of institutional investors including both domestic and foreign investors could affect futures returns differently.

Combining the two effects from the day-of-the-week effect and different types of institutional investors, we propose our fourth hypothesis as follows:

Hypothesis 4: The day-of-the-week effect for different types of institutional investors will have its respective positive influences on futures returns.

\section{Data and Methodology}

\subsection{Data Sources}

The data used in this study are mainly sourced from the Taiwan Futures Exchange for the period from January 2, 2008 to March 18, 2009. The data type are tick-by-tick transaction data. The information in the trade book includes the name of the futures contract, the expiration date of the futures contract, the trading price, trading volume, trading direction, trading time, especially, and the identity of traders.

\subsection{Methodology}

\subsubsection{Volume-Synchronized Probability of Informed Trading}

To calculate the VPIN, Easley et al. (2012) divided the daily trading volume into multiple pieces $N$ according to the volume of buys and sells. With this integrated information, the VPIN can be computed. Regarding the transaction volume $\tau$, the volume of buys is $V_{\tau}^{B}$, the volume of sells is $V_{\tau}^{S}$, and the total volume is $V_{\tau}$. Obviously, $V_{\tau}=V_{\tau}^{B}+V_{\tau}^{S}$ is based on the basic theoretical model of the PIN. The expectation for the unbalanced trading volume of the VPIN is: 


$$
E\left(\left|V_{\tau}^{B}-V_{\tau}^{S}\right|\right)=|\varepsilon+\alpha * \delta * \mu-[\varepsilon+\alpha *(1-\delta) * \mu]|=\alpha \mu|1-2 \delta|
$$

Owing to the assumption regarding the initial point from the PIN, at the beginning of the trading day, the probability for good and bad news will be equal is $\delta=0.5$ and so $E\left(\left|V_{\tau}^{B}-V_{\tau}^{s}\right|\right) \approx \alpha \mu$. Thus, the VPIN for the day is:

$$
V P I N=\frac{\alpha \mu}{\alpha \mu+2 \varepsilon} \approx \frac{1}{N} \sum_{t=N}^{N} \frac{\left|V_{\tau}^{S}-V_{\tau}^{B}\right|}{V_{\tau}} .
$$

In view of the use of high frequency data sources for the Taiwan Futures Exchange, we choose the TR-VPIN method to verify the VPIN.

\subsubsection{The Influence on Futures Returns}

We use the GARCH model to estimate the influence of futures returns and different identities of traders with the probability of informed trading and trading volume being the main factors influencing the futures returns. The main reason why we use the GARCH model to estimate the futures returns is based on volatility clustering, which is the characteristic of financial time series. Transactions in futures options markets reflect the trader in regard to trading assets and views regarding future trends in Taiwan's financial markets. Such transaction data will become the effective information for investors in the Taiwan stock index and Taiwan index futures. At the same time, the date of the transaction itself is also effective public information. The diverse identities of the investors and the way they treat this information should be different. Therefore, the models below seek to examine the influence of probability-informed trading on the futures returns.

According to the papers mentioned above, we would like to investigate whether the day-of-the-week effect will have an impact on futures returns, especially on Mondays, Wednesdays and Fridays, and to this end we come up with Model 1 below:

$$
\begin{gathered}
R_{t}=\mu_{0}+\mu_{1} R_{t-1}+u_{2} P C R_{t-1}+u_{3} V_{t-1}+u_{4} W 1+u_{5} W 3+u_{6} W 5+\varepsilon_{t} \\
\sigma_{t}^{2}=\alpha_{0}+\alpha_{1} \varepsilon_{t-1}^{2}+\beta \sigma_{t-1}^{2}
\end{gathered}
$$

where the $R_{t}$ are futures returns at time $t . \mu_{0}$ is a constant. PCR is the put call ratio at time $t-1 . V_{t-1}$ is the volume of futures at time $t-1$. The dummy variable $W 1$ means Mondays, W3 means Wednesdays and W5 means Fridays. This equation arises as a result of our Hypothesis 1, which is that the day-of-the-week effect affects futures returns, especially on Mondays, Wednesdays and Fridays. Note that a statistically significant $\mu_{l}$ implies the existence of price inefficiency. The GARCH model has two characteristic parameters, one being $u_{t-1}^{2}$ or the ARCH term and the other $\sigma_{t-1}^{2}$ being the GARCH term (Note 3).

In the equation for Model 2, we would like to find out whether the VPIN for all investors will impact futures returns:

$$
\begin{gathered}
R_{t}=\mu_{0}+\mu_{1} R_{t-1}+u_{2} V P I N 0_{t-1}+u_{3} \operatorname{VPINO}_{t-1}^{2}+u_{4} P C R_{t-1}+u_{5} V_{t-1}+\varepsilon_{t} \\
\sigma_{t}^{2}=\alpha_{0}+\alpha_{1} \varepsilon_{t-1}^{2}+\beta \sigma_{t-1}^{2}
\end{gathered}
$$

where VPIN $0_{t-1}$ is the probability of informed trading for all investors at time $t-1$. According to our Hypothesis 2-1, we expect the coefficient $\mu_{2}$ to be positive.

In the equation for Model 3, we would like to investigate whether the VPIN for all investors with the day-of-the-week effect will have an influence on futures returns (Note 4):

$$
\begin{gathered}
R_{t}=\mu_{0}+\mu_{1} R_{t-1}+u_{2} \operatorname{VPINO}_{t-1}+u_{3} \operatorname{VPINO}_{t-1}^{2}+u_{4} P C R_{t-1}+u_{5} V_{t-1}+u_{6} W \times \operatorname{VPINO}_{t-1}+\varepsilon_{t} \\
\sigma_{t}^{2}=\alpha_{0}+\alpha_{1} \varepsilon_{t-1}^{2}+\beta \sigma_{t-1}^{2}
\end{gathered}
$$

where $W \times V P I N 0_{t-1}$ represents a weekday with the probability of informed trading for all investors. According to our Hypothesis 2-2, we expect the coefficient $u_{6}$ to be positive, indicating the returns will be affected by informed traders with the day-of-the-week effect.

In the equation for Model 4, we would like to determine the VPINs for domestic and foreign institutional investors and their impact on futures returns: 


$$
\begin{gathered}
R_{t}=\mu_{0}+\mu_{1} R_{t-1}+u_{2} V P I N 1_{t-1}+u_{3} V P I N 2_{t-1}+u_{4} V P I N 1_{t-1}^{2}+u_{5} V P I N 2_{t-1}^{2}+u_{6} P C R_{t-1}+u_{7} V_{t-1}+\varepsilon_{t} \\
\sigma_{t}^{2}=\alpha_{0}+\alpha_{1} \varepsilon_{t-1}^{2}+\beta \sigma_{t-1}^{2}
\end{gathered}
$$

where VPIN $1_{t-1}\left(V P I N 2_{t-1}\right)$ is the probability of informed trading for domestic (foreign) investors at time $t-1$. Following our Hypothesis 3, we expect the coefficients $\mu_{2}$ and $\mu_{3}$ are significant.

In the equation for model 4, we mainly want to examine the extent to which the VPINs of domestic and foreign institutional investors with the day-of-the-week effect will affect the futures returns:

$$
\begin{gathered}
R_{t}=\mu_{0}+\mu_{1} R_{t-1}+u_{2} V P I N 1_{t-1}+u_{3} V P I N 2_{t-1}+u_{4} V P I N 1_{t-1}^{2}+u_{5} V P I N 2_{t-1}^{2}+u_{6} P C R_{t-1}+u_{7} V_{t-1} \\
+u_{8} W \times V P I N 1_{t-1}+u_{9} W \times V P I N 2_{t-1}+\varepsilon_{t} \\
\sigma_{t}^{2}=\alpha_{0}+\alpha_{1} \varepsilon_{t-1}^{2}+\beta \sigma_{t-1}^{2}
\end{gathered}
$$

where $W \times V P I N 1_{t-1}\left(W \times V P I N 2_{t-1}\right)$ represents a weekday with the probability of informed trading for domestic (foreign) investors at time $t-1$. In line with our Hypothesis 4 , we expect the coefficients $\mu_{8}$ and $\mu_{9}$ to be significant statistically.

\section{Empirical Results}

Table 1 presents the descriptive statistics for futures returns $(R)$, the put call ratio $(P C R)$, the VPIN of all investors (VPINO), the VPIN of the domestic institutional investors (VPINI), the VPIN of the foreign institutional investors (VPIN2) and the volume of futures $(V)$. The mean of $R$ is -0.1346 , VPIN0 is 0.0431 , VPIN1 is 0.6548 and VPIN2 is 0.3724 (Note 5). The standard deviation of $R$ is 2.5535 , VPIN0 is 0.0328 , VPIN1 is 0.0923 and VPIN2 is 0.1427 . All of the variable series are negatively skewed, except for VPIN0, whereas most of the kurtosis statistics indicate that the series are distributed leptokurtically, except for VPIN2. The Jarque-Bera test statistics are non-normally distributed. According to this descriptive statistics test, the Jarque-Bera coefficient is significant at the $5 \%$ level; that is, these data are not normally distributed.

Table 1. Descriptive statistics of variables

\begin{tabular}{lcccccc}
\hline & $R$ & $P C R$ & $V P I N 0$ & $V P I N 1$ & $V P I N 2$ & $V$ \\
\hline Mean & -0.1346 & 0.4062 & 0.0431 & 0.6548 & 0.3724 & 11.6512 \\
Median & 0.0384 & 0.4109 & 0.0375 & 0.6636 & 0.3867 & 11.6504 \\
Maximum & 6.9906 & 0.5469 & 0.5499 & 1.0000 & 0.7650 & 12.4643 \\
Minimum & -7.0000 & 0.1835 & 0.0192 & 0.2114 & 0.0751 & 8.2228 \\
Std. Dev. & 2.5535 & 0.0565 & 0.0328 & 0.0923 & 0.1427 & 0.3759 \\
Skewness & -0.0016 & -0.5138 & 12.8010 & -0.2868 & -0.1438 & -3.0056 \\
Kurtosis & 3.7230 & 3.7806 & 196.4178 & 4.6900 & 2.3362 & 27.2591 \\
Jarque-Bera & $6.4041^{* *}$ & $20.3988^{* * *}$ & $466307.30 * * *$ & $39.0182^{* * *}$ & $6.4110^{* *}$ & $7651.8340^{* * *}$ \\
\hline
\end{tabular}

Note. *, **, and *** denote significance at the $10 \%, 5 \%$ and $1 \%$ levels, respectively. $R$ is futures returns; VPIN0 is the VPIN of all investors; VPIN1 is the VPIN of the domestic institutional investors; VPIN2 is the VPIN of the foreign institutional investors; PCR is the put call ratio; and $V$ is volume.

Table 2 presents the results of the unit root test. We use two unit root tests, the augmented Dickey-Fuller (ADF)

\begin{tabular}{|c|c|c|c|c|c|c|}
\hline & \multicolumn{3}{|c|}{ Augmented Dickey-Fuller test } & \multicolumn{3}{|c|}{ Phillips-Perron test } \\
\hline & $\mathrm{t}$-Statistic & Prob. & Lag Length & Adj. t-Stat & Prob. & Bandwidth \\
\hline$R$ & $-9.4922 * * *$ & $<0.0001$ & 3 & $-17.9265^{* * *}$ & $<0.0001$ & 13 \\
\hline$P C R$ & $-8.9955 * * *$ & $<0.0001$ & 0 & $-9.1911 * * *$ & $<0.0001$ & 6 \\
\hline VPINO & $-15.2065^{* * *}$ & $<0.0001$ & 0 & $-15.3460 * * *$ & $<0.0001$ & 6 \\
\hline VPIN1 & $-8.8437 * * *$ & $<0.0001$ & 1 & $-16.0884 * * *$ & $<0.0001$ & 10 \\
\hline VPIN2 & $-8.1289 * * *$ & $<0.0001$ & 0 & $-8.1780 * * *$ & $<0.0001$ & 2 \\
\hline V & $-5.0276 * * *$ & 0.0002 & 4 & $-13.8656^{* * * *}$ & $<0.0001$ & 10 \\
\hline
\end{tabular}
test and the Phillips-Perron (PP) test. We find that both of the ADF and PP test are significant at the $1 \%$ level to reject the null hypothesis of nonstationary series, which imply that all variables used in our study are stationary series and do not need to concern the problem of spurious relationship.

Table 2. Unit root tests

Note. *, **, and *** denote significance at the $10 \%, 5 \%$ and $1 \%$ levels, respectively. $R$ is futures returns; VPIN0 is the VPIN of all investors; VPIN1 is the VPIN of the domestic institutional investors; VPIN2 is the VPIN of the foreign institutional investors; PCR is the put call ratio; and $V$ is volume. 
Table 3 presents the descriptive statistics for each weekday returns. We can find that only the means for Wednesdays and Fridays are positive. The highest mean of futures returns is on Wednesdays (i.e., 0.2561), and the lowest two ones are on Tuesdays (i.e., -0.4408) and on Thursdays (i.e., -0.7192). Based on these results for higher futures returns on Wednesdays than other days, we can infer that there might be a special kind of day-of-the-week effect in the Taiwan futures market. Thus, we would need to take these day-of-the-week effect of futures returns into consideration.

Table 3. Descriptive statistics of weekday returns

\begin{tabular}{ccccc}
\hline WEEKDAY & Mean & Max & Min. & Std. Dev. \\
\hline Monday & -0.025195 & 6.987300 & -6.986400 & 2.787355 \\
Tuesday & -0.440800 & 6.990600 & -6.991400 & 2.740656 \\
Wednesday & 0.256102 & 5.111000 & -5.990400 & 1.889878 \\
Thursday & -0.719227 & 6.986500 & -7.000000 & 2.836604 \\
Friday & 0.237414 & 6.990200 & -5.268800 & 2.404229 \\
All & -0.134646 & 6.990600 & -7.000000 & 2.553471 \\
\hline
\end{tabular}

Table 4 shows the results of the day-of-the-week effect using the $\operatorname{GARCH}(1,1)$ model (Note 6). In consideration of the special effects of the day-of-the-week effect, we estimate the returns of the day-of-the-week effect for Mondays, Wednesdays and Fridays using the $\operatorname{GARCH}(1,1)$ model (Note 7). We can find the coefficient for Wednesdays is 0.9192 and is also significant at the 5\% level. However, for Mondays and Fridays, both of their coefficients are 0.4651 and 0.5549 , but all of them are not significant. Overall, we can conclude that our Hypothesis 1 is supported in that a day-of-the-week effect is found to exist on Wednesdays (Note 8).

Table 4. The impact of the day-of-the-week effect on returns

\begin{tabular}{lcccc}
\hline & & & & \\
\hline Variable & Coefficient & Std. Error & t-Statistic & Prob. \\
\hline$R_{t-1}$ & -0.0394 & 0.0678 & -0.5816 & 0.5608 \\
$\mu_{0}$ & -5.7055 & 5.1982 & -1.0976 & 0.2724 \\
$P C R_{t-1}$ & -0.7313 & 2.2879 & -0.3196 & 0.7493 \\
$V_{t-1}$ & 0.4814 & 0.4384 & 1.0982 & 0.2721 \\
$W 1$ & 0.4651 & 0.3114 & 1.4936 & 0.1353 \\
$W 3$ & $0.9192^{* *}$ & 0.4204 & 2.1864 & 0.0288 \\
$W 5$ & 0.5549 & 0.3409 & 1.6279 & 0.1036 \\
$\alpha_{0}$ & 0.0809 & 0.0748 & 1.0819 & 0.2793 \\
$\alpha_{1}$ & $0.0825 * *$ & 0.0349 & 2.3642 & 0.0181 \\
$\beta$ & $0.9042^{* * *}$ & 0.0375 & 24.0925 & 0.0000 \\
\hline Sum squared residual & 1857.3310 & LB(4) & 1.1995 & \\
Log likelihood & -663.9121 & LB squared(4) & 4.0627 & \\
Durbin-Watson stat. & 1.9765 & ARCH(4) & 4.1620 & \\
Akaike info criterion & 4.6001 & Joint test & 1.1359 & \\
\hline
\end{tabular}

Note. *, **, and *** denote significance at the $10 \%, 5 \%$ and $1 \%$ levels, respectively. $R$ is futures returns; $P C R$ is the put call ratio; $V$ is the volume of futures. $W_{1}$ is Monday; $W_{3}$ is Wednesday; $w_{5}$ is Friday; $\mathrm{LB}(\mathrm{n})$ and $\mathrm{LB}(\mathrm{n})$ squared are the Ljung-Box Q test of serial correlation in the residuals for level and squared; $\mathrm{ARCH}(\mathrm{N})$ is the Lagrange Multiplier LM test for ARCH effects and is distributed as a $\chi^{2}$ distribution with $\mathrm{N}$ degrees of freedom. The test results for the joint test are Engle and $\mathrm{Ng}$ 's (1993) test for the potential asymmetries in conditional volatility. Model 2: $R_{t}=\mu_{0}+\mu_{1} R_{t-1}+u_{2} W 1_{t-1}+u_{3} W 3_{t-1}+u_{4} W 5_{t-1}+u_{5} P C R_{t-1}+u_{6} V_{t-1}+\varepsilon_{t}$ and $\sigma_{t}^{2}=\alpha_{0}+\alpha_{1} \varepsilon_{t-1}^{2}+\beta \sigma_{t-1}^{2}$.

Finally, in order to take the impact of the VPIN of investors on futures returns into consideration, we use Wednesdays as our multiplication factor to estimate the $\operatorname{GARCH}(1,1)$ model on Table (Note 9). For Model 2 as shown in Table 5, the coefficient of $R_{t-1}$ is negative but not significant. The coefficient of $V P I N O_{t-1}$ is also not significant, indicating that the futures returns are not influenced by the VPIN for all investors. According to our Hypothesis 2-2, this result evidently is not in accordance with our expectations. Besides, for Model 3, the 
coefficient of VPINO $0_{t-1}$ is -20.5303 and is not significant, indicating that the futures returns are not influenced by the VPIN for all investors. However, the coefficient of $W 3 \times V P I N O_{t-1}$ is 13.8527 and is positive significantly at the 5\% level, implying that the VPIN for all investors on Wednesday affects the futures returns positively. This reconfirms our Hypothesis 2-2 that informed traders on Wednesday have a positive effect on futures returns.

Table 5. The impact of the VPIN for all investors and the institutional investors on returns; with the impact of a day-of-the-week effect on returns

\begin{tabular}{|c|c|c|c|c|c|c|c|c|}
\hline \multirow[b]{2}{*}{$R_{t-1}$} & \multicolumn{2}{|c|}{ Model 2} & \multicolumn{2}{|c|}{ Model 3} & \multicolumn{2}{|c|}{ Model 4} & \multicolumn{2}{|c|}{ Model 5} \\
\hline & -0.0690 & $(0.0611)$ & -0.0593 & $(0.0633)$ & -0.0648 & $(0.0611)$ & -0.0580 & $(0.0626)$ \\
\hline$\mu_{0}$ & -1.5108 & $(5.8143)$ & 0.6781 & $(5.8630)$ & -2.4860 & $(6.8956)$ & -2.0243 & (6.8066) \\
\hline $\operatorname{VPIN0}_{t-1}$ & -12.5364 & (13.7101) & -20.5303 & (14.6107) & & & & \\
\hline$V P I N 1_{t-1}$ & & & & & 1.8417 & (11.1953) & 0.3546 & (10.6391) \\
\hline VPIN $2_{t-1}$ & & & & & $7.2557 * *$ & $(4.0492)$ & $10.8144^{* *}$ & $(4.5137)$ \\
\hline$V_{P I N 0^{2}}^{2}$ & 10.4796 & $(21.6872)$ & 22.8175 & $(23.0931)$ & & & & \\
\hline$V P I N 1_{t-1}^{2}$ & & & & & -3.0132 & (8.9694) & -2.2006 & (8.5457) \\
\hline$V P I N 2^{2}{ }_{t-1}$ & & & & & $-9.6854 * *$ & $(5.3243)$ & $-13.6239^{* *}$ & (5.5643) \\
\hline$P C R_{t-1}$ & -0.9404 & $(2.7753)$ & -1.3400 & $(2.7590)$ & -0.1808 & $(2.8805)$ & -0.2832 & $(2.8625)$ \\
\hline$V_{t-1}$ & 0.2033 & $(0.4687)$ & 0.0458 & $(0.4744)$ & 0.1273 & $(0.5770)$ & 0.0723 & $(0.5766)$ \\
\hline$W 3 \times V P I N 0_{t-1}$ & & & $13.8527 * *$ & $(5.7556)$ & & & & \\
\hline$W 3 \times V P I N 1_{t-1}$ & & & & & & & $2.4425^{* *}$ & (1.1389) \\
\hline$W 3 \times V P I N 2_{t-1}$ & & & & & & & -2.3743 & (1.8008) \\
\hline$\alpha_{0}$ & 0.0764 & $(0.0850)$ & 0.0811 & $(0.0859)$ & 0.0661 & $(0.0770)$ & 0.0638 & $(0.0724)$ \\
\hline$\alpha_{1}$ & $0.0761 * *$ & $(0.0307)$ & $0.0804 * *$ & $(0.0322)$ & $0.0797 * *$ & $(0.0321)$ & $0.0876^{* * *}$ & $(0.0331)$ \\
\hline$\beta$ & $0.9116^{* * *}$ & $(0.0388)$ & $0.9066^{* * *}$ & $(0.0400)$ & $0.9098^{* * *}$ & $(0.0391)$ & $0.9027 * * *$ & $(0.0386)$ \\
\hline Log likelihood & -667.3083 & & -665.4171 & & -665.5898 & & -662.3960 & \\
\hline $\begin{array}{l}\text { Durbin-Watson } \\
\text { stat. }\end{array}$ & 1.9674 & & 1.9627 & & 2.0030 & & 1.9859 & \\
\hline AIC & 4.6164 & & 4.6104 & & 4.6184 & & 4.6102 & \\
\hline $\mathrm{LB}(4)$ & 1.4739 & & 1.0413 & & 1.0798 & & 1.0352 & \\
\hline LB squared(4) & 5.0996 & & 4.2284 & & 5.2855 & & 4.5174 & \\
\hline $\mathrm{ARCH}(4)$ & 5.4282 & & 4.4093 & & 5.4732 & & 4.4761 & \\
\hline Joint test & 2.6668 & & 1.5499 & & 3.2556 & & 1.9181 & \\
\hline
\end{tabular}

Note. $R$ is futures returns; VPIN0 is the VPIN for all investors;VPIN1 is the VPIN of the domestic institutional investors; VPIN2 is the VPIN of foreign institutional investors; $P C R$ is the put call ratio; $V$ is the volume of futures; $W 3 \times V P I N 0_{t-1}$ is Wednesday multiplied by the VPIN for all investors; $W 3 \times V P I N 1_{t-1}$ is Wednesday multiplied by the VPIN of the domestic institutional investors; $W 3 \times V P I N 2_{t-1}$ is Wednesday multiplied by the VPIN of all foreign institutional investors; $\alpha_{0}$ is a constant; $\alpha_{1}$ and $\beta$ are empirical parameters; LB(n) and LB(n) squared are the Ljung-Box Q test of serial correlation for level and squared; and ARCH(N) is the Lagrange Multiplier LM test for the ARCH effects that is distributed as a $\chi^{2}$ distribution with $\mathrm{N}$ degrees of freedom. The test results for the joint test are Engle and Ng's (1993) test for the potential asymmetries in conditional volatility. *,**, and *** denote significance at the $10 \%, 5 \%$ and $1 \%$ levels, respectively.

After obtaining the above results and considering the specificity of our data, we go further to distinguish the traders into domestic and foreign institutional investors in Model 4, and then add the multiplication factor for Wednesday in Model 5. At first, in Model 4, we can find that the coefficient of $V_{P I N 1_{t-1}}$ is 1.8417 but it is not significant, indicating that the futures returns are not influenced by the VPIN of the domestic institutional investors. Besides, the coefficient of VPIN2 ${ }_{t-1}$ is 7.2557 and is significant at the $5 \%$ level, indicating that the VPIN of the foreign institutional investors significantly affects the futures returns. Overall, these results support our Hypothesis 3, which illustrate the forecasting ability for futures returns of foreign investors and is also consistent with Lai and Wang (2014).

Finally, in Model 5, we can find that the coefficient of $V P I N 1_{t-1}$ is 0.3546 but is not significant, again indicating 
that the futures returns are not influenced by the VPIN of the domestic institutional investors. However, the coefficient of ${ }_{V P I N 2_{t-1}}$ is 10.8144 and is significant at the $5 \%$ level, implying that the VPIN of the foreign institutional investors affects the futures returns. The coefficient of the interaction term $W 3 \times V P I N 1_{t-1}$ is 2.4425 and is significant at the $5 \%$ level; the coefficient of $W 3 \times V P I N 2_{t-1}$ is -2.3743 and is not significant. Based on these results, we can infer that the VPIN of the domestic institutional investors on Wednesdays indeed significantly affects the futures returns. In addition, we also compare these four models based on several criterions (i.e., from Model 2 to Model 5), including the sum of squared residuals, log likelihood, the Durbin-Watson statistic, and the Akaike information criterion (AIC). Overall, we can find that Model 5 should be the best model. Hence, if we choose Model 5 as our main inference, we can conclude that the day-of-the-week effect for different types of institutional investors indeed have its respective influences on futures returns, which is also in support of our Hypothesis 4.

\section{Conclusion}

The main purpose of this paper is to discuss the influence of the probability of informed trading on Taiwan futures over the period from January 2, 2008 to March 18, 2009 using unique data from the Taiwan futures exchange. Due to the special feature of the day-of-the-week effect in financial markets, we also observe the VPIN for different types of trading investors with a weekday effect that impacts on futures returns. The empirical results show that the probability of informed trading for individual traders and institutional investors, which do not significantly impact the futures returns. Moreover, as we go further to divided the institutional investors into foreign and domestic investors, we find that the probability of informed trading from the foreign institutional investors has significant impacts on the futures returns, but no impacts from domestic investors. Besides, regarding the results for the day-of-the-week effect, we can find that the effect of the VPIN of domestic institutional investors on futures returns is only significant on Wednesdays, which indeed could be seen as a special kind of day-of-the-week effect. These empirical results are also consistent with the findings in literature.

In conclusion, we fill the gap in the literature and contribute to the field of research about the probability of informed trading, especially providing the new findings regarding the impacts of investors' identities and day-of-the-week effect on futures markets. That is, we find that the probability of the informed trading from foreign institutional traders influence Taiwan futures returns. Besides, the probability of the informed trading from domestic institutional traders has a significant impact on futures returns only on Wednesdays.

\section{References}

Bailey, W., Cai, J., Cheung, Y. L., \& Wang, F. (2009). Stock returns, order imbalances, and commonality: Evidence on individual, institutional, and proprietary investors in China. Journal of Banking \& Finance, 33, 9-19. https://doi.org/10.1016/j.jbankfin.2006.08.007

Che, H., Xiong, X., Han, J., Zhang, W., \& Zhang, Y. (2014). Study on informational transaction and its effect on China's stock index futures market. Mathematical Problems in Engineering, 2014, 1-10. http://dx.doi.org/10.1155/2014/272403

Cross, F. (1973). The behavior of stock prices on Fridays and Mondays. Financial Analysts Journal, 29, 67-69. https://doi.org/10.2469/faj.v29.n6.67

Easley, D., Engle, T. F., O’Hara, M., \& Wu, L. (2008). Time-varying arrival rates of informed and uninformed trades. Journal of Financial Econometrics, 6, 171-207. https://doi.org/10.1093/jjfinec/nbn003

Easley, D., Hvidkjaer, S., \& O'Hara, M. (2002). Is information risk a determinant of asset returns? Journal of Finance, 57, 2185-2221. https://doi.org/10.1111/1540-6261.00493

Easley, D., Kiefer, N. M., O’Hara, M., \& Paperman, J. B. (1996). Liquidity, information, and infrequently traded stocks. Journal of Finance, 51, 1405-1436. http://doi.org/10.1111/j.1540-6261.1996.tb04074.x

Easley, D., O’Hara, M., \& Srinivas, P. S. (1998). Option volume and stock prices: Evidence on where informed traders trade. Journal of Finance, 53, 431-465. http://doi.org/10.1111/0022-1082.194060

Easley, D., Prado, M. M. L., \& O’Hara, M. (2011a). The microstructure of the "Flash Crash": Flow toxicity, liquidity crashes, and the probability of informed trading. Journal of Portfolio Management, 37, 118-128. http://doi.org/10.3905/jpm.2011.37.2.118

Easley, D., Prado, M. M. L., \& O’Hara, M. (2011b). The exchange of flow toxicity. Journal of Trading, 6, 8-13. 
http://doi.org/10.3905/jot.2011.6.2.008

Easley, D., Prado, M. M. L., \& O'Hara, M. (2012). Flow toxicity and liquidity in a high frequency world. Review of Financial Studies, 25, 1457-1493. https://doi.org/10.1093/rfs/hhs053

Fields, M. J. (1931). Stock prices: A problem in verification. Journal of Business, 7, 415-418. http://dx.doi.org/10.1086/232221

French, K. R. (1980). Stock returns and the weekend effect. Journal of Financial Economics, 8, 55-69. https://doi.org/10.1016/0304-405X(80)90021-5

Harris, L. (1986). Transaction data study of weekly and internal patterns in stock returns. Journal of Financial Economics, 16, 99-117. https://doi.org/10.1016/0304-405X(86)90044-9

Lai, H. C., \& Wang, K. M. (2014). Relationship between the trading behavior of three institutional investors and Taiwan stock index futures returns. Economic Modelling, 41, 156-165. https://doi.org/10.1016/j.econmod.2014.05.007

Lien, D., Tseng, M. C., \& Wu, S. (2013). Foreign investors in Taiwan: Their roles and government perspectives. Business Horizons, 56, 749-756. https://doi.org/10.1016/j.bushor.2013.07.007

Lin, A., \& Chen, C. Y. (2006). The impact of Qualified Foreign Institutional Investors on Taiwan's stock market. Web Journal of Chinese Management Review, 9, 1-27.

Sias, R. W., \& Starks, L. T. (1997). Return autocorrelation and institutional investors. Journal of Financial Economics, 46, 103-131. https://doi.org/10.1016/S0304-405X(97)00026-3

Xu, F., \& Wan, D. (2015). The impacts of institutional and individual investors on the price discovery in stock index futures market: Evidence from China. Finance Research Letters, 15, 221-231. https://doi.org/10.1016/j.frl.2015.10.002

Yan, Z., Cheng, L. Y., Zhao, Y., \& Huang, C. Y. (2016). Daily short covering activity and the weekend effect: Evidence from Taiwan. Pacific-Basin Finance Journal, 36, 166-184. https://doi.org/10.1016/j.pacfin.2015.12.008

Zhan, S. H., \& Wang, J. L. (2007). The day-of-the-week effect in Taiwan weighted stock price index: An analysis of investors' trading activities. Operating Management Reviews, 3, 47-58.

\section{Notes}

Note 1. Taiwan began to implement the policy of two days off per week on January 1, 2001 and also changed the trading day.

Note 2. They examined the following indexes, including Hang Seng Index of Hong Kong, Jakarta Composite Index of Indonesia, Kuala Lumpur Composite Index of Malaysia, Nikkei Index of Japan, Straits Times Index of Singapore, Taiwan Stock Exchange Index of Taiwan, and SET Index of Thailand.

Note 3. $\alpha_{1}$ and $\beta$, empirical parameters determined by maximum likelihood estimation, are non-negative scalars such that the default constraint is $\alpha_{1}+\beta<1$. In addition, it should be noted that $\alpha_{1}+\beta<1$ is required for stationarity. The more that the sum of the two coefficients, $\alpha_{1}+\beta$, approaches unity, the greater the persistence of shocks to the variance.

Note 4. According to our empirical results, we find that Wednesday is highly related to the returns on futures.

Note 5. The range between the maximum and minimum of the returns is from 6.9906 to -7.0000 , which represents the $7 \%$ limit on returns in the Taiwan futures market.

Note 6. In diagnostic checks, LB(4) and LB squared(4) are not significant, implying that there is no serial correlation in the residuals for both level and squared values. Besides, the ARCH(4) effect is not significant, indicating that the residual does not exhibit time-varying heteroscedasticity. We conduct a joint test for potential asymmetries in conditional volatility but our results show that it is not significant. Based on these results, we choose to adopt the GARCH $(1,1)$ model as our main detection model.

Note 7. According to previous research, Mondays, Wednesdays and Fridays influence returns in the financial market. Our results for the descriptive statistics also indicate that Mondays have the lowest mean for the returns and Wednesdays have the highest mean for the returns in as shown in Table 3.

Note 8. Our results are consistent with the finding of Yan, Cheng, Zhao and Huang (2016). They examine the 
relationship between the daily short covering activity and the weekend effect of Taiwan Stock Exchange, and they also find that Wednesday's returns are the highest and Friday's returns are higher than Monday's returns.

Note 9. The volume of futures transactions in Model 2 to Model 5 can be explained by both the lagged squared innovations and the lagged volume given significant values of $\alpha_{l}$ and $\beta_{l}$ at the 5\% level. The summary statistics for Model 2 to Model 5 are provided in Table 5. The table shows clear evidence of normality due to there not being significant $\mathrm{ARCH}(4)$ effects. A joint test for potential asymmetry in conditional volatility is conducted, but our results show that it is not significant and suggest that there is symmetry from Model 2 to Model 5.

\section{Copyrights}

Copyright for this article is retained by the author(s), with first publication rights granted to the journal.

This is an open-access article distributed under the terms and conditions of the Creative Commons Attribution license (http://creativecommons.org/licenses/by/4.0/). 